\title{
NECESSIDADES FORMATIVAS E FORMAÇÃO DE COMPETÊNCIAS: desafios na profissionalização docente para a melhoria da educação básica CONSTRUCTIVE NECESSITIES AND COMPETENCE FORMATION: challenges in
} teacher professional training for basic education improvement

\author{
Ilzeni Silva Dias ${ }^{1}$ \\ Helianane O. Rocha ${ }^{2}$ \\ Raimunda Ramos Marinho ${ }^{3}$
}

\section{RESUMO}

O presente artigo traz reflexões iniciais resultantes da pesquisa Necessidades Formativas e Formação de Competências nos Cursos de Primeira Licenciatura do PARFOR/UFMA: desafios para o desenvolvimento de práticas pedagógicas inovadoras nas escolas públicas do Maranhão. Neste estudo, tomou-se como eixo de análise as inovações científicas e tecnológicas, sobretudo pelo papel significativo que a ciência e a tecnologia tiveram no aumento da produção de bens materiais, além das grandes contribuições ao longo dos séculos para o desenvolvimento das forças produtivas. Com efeito, este estudo tem como objetivo analisar as necessidades formativas e formação de competências nos cursos de primeira licenciatura do PARFOR/UFMA, buscando contribuir para o desenvolvimento de práticas pedagógicas inovadoras nas escolas públicas, assim como para a qualidade da educação básica no estado do Maranhão. Conclui-se que são as mudanças na produção de bens materiais, em cada momento histórico e em cada espaço geográfico, que definem e impõem as novas necessidades formativas, exigindo, em consequência, novos perfis profissionais.

Palavras-chave: Ciência. Tecnologia. Necessidades Formativas. Educação Básica.

\begin{abstract}
This article presents initial reflections as a result of the research on Training Needs and Skills Development in the PARFOR / UFMA First Degree (Licenciate) Courses: challenges for the development of innovative pedagogical practices in the public schools of Maranhão. In this study, scientific and technological innovations were taken as the axis of analysis based on the understanding that science and technology have not only played a significant role in increasing the production of material goods, but also made great contributions to the development of the productive forces over the centuries. The aim of this study is to analyze the training needs and competencies development in 1st degree (licenciate) courses of the PARFOR Program at UFMA, seeking to add to the development of innovative pedagogical practices in public schools, as well as to the improvement of basic education in the State of Maranhão. It is concluded that it is the changes produced in the production of material goods in each historical moment and in each geographical space that define and impose new training needs, requiring new professional profiles according to the requirements of each period and place.
\end{abstract}

\footnotetext{
${ }^{1}$ Professora Associada Departamento de Educação II - UFMA. E-mail: silvadias2612@gmail.com

${ }^{2}$ Professora Adjunta Departamento de Educação II - UFMA. E-mail: helianane@yahoo.com.br

${ }^{3}$ Professora Adjunta Departamento de Biblioteconomia - UFMA. E-mail: rr.marinho@ufma.br
} 
Keywords: Science. Technology. Training Needs. Basic Education.

\section{REFLEXÕES PRELIMINARES: DESAFIOS NA PROFISSIONALIZAÇÃO DOCENTE}

Este estudo tem como ponto de partida o reconhecimento de que a ciência e a tecnologia fazem parte da história do desenvolvimento da humanidade, visto que esses dois campos, em seus diferentes estágios de desenvolvimento, tempos históricos e espaços geográficos, que contribuíram significativamente para a produção de bens materiais ao longo da história da humanidade.

Ciência e tecnologia, por um lado, tiveram papel fundamental no aumento da produção de bens materiais e deram grandes contribuições ao longo dos séculos para o desenvolvimento das forças produtivas, as quais provocaram um turbilhão de mudanças na produção da vida material. Outrossim, foram lentamente impondo novos conceitos, hábitos e costumes, definindo novas formas de organização do trabalho, novos padrões de comportamento humano, e exigindo novas relações de produção e de trabalho.

A partir desse reconhecimento, não se pode negar que as profundas transformações, que foram inevitáveis ao longo dos séculos, tornaram-se um campo fértil para elaboração de novas ideias. As mudanças produzidas na produção de bens materiais e as novas ideias que delas brotaram não só impactaram profundamente o cenário econômico, político, social e cultural, em cada momento histórico e em cada espaço geográfico, mas também fertilizaram o campo de conflitos entre o velho e o novo nos espaços de trabalho, dando novos contornos a esses espaços e exigindo novos perfis profissionais.

Essa realidade aumentou as preocupações da sociedade em geral, sobretudo no que tange aos desafios da educação impostos pela sociedade do século XXI, o que exige uma nova consciência no que se refere às políticas públicas de educação, com ênfase na formação de professores que atuam na educação básica. Em complemento, segundo o Anuário da Educação Básica “Todos pela Educação” (2016, p. 04),

\footnotetext{
Nas últimas décadas, consolidou-se a consciência de que a Educação deve ser, antes de tudo, uma política de Estado, que conduza o Brasil a conquistas de longo prazo, independentemente da alternância natural de governos. Prova disso é a própria existência do Plano Nacional de Educação (PNE), sancionado em junho de 2014, que traz metas e diretrizes a serem alcançadas no prazo de dez anos e, assim, constitui a agenda estratégica da Educação brasileira.
} 
No Brasil, os dados estatísticos refletem o quadro real da formação dos professores da educação básica, chamando mais a atenção daqueles que compartilham do esforço pela melhoria da qualidade desse nível de ensino, em particular nas escolas públicas. O fato é que "cerca de um quarto dos profissionais ainda não tem formação superior. Trata-se de uma realidade muito distante daquela que o PNE vislumbra para 2024 - $100 \%$ dos professores com a formação específica de nível superior" (TODOS PELA EDUCAÇÃO, 2016, p. 106).

De acordo com os dados do Censo Escolar (BRASIL, 2016), no Brasil são 2,2 milhões de professores na Educação Básica, dentre os quais 77,5\% possuem Ensino Superior completo. Desse total, têm-se $6,5 \%$ em processo de formação; $11,1 \%$ possuem o normal/magistério; 4,6\% o Ensino Médio; 0,2\% o Ensino Fundamental completo; e 0,1\% o Ensino Fundamental incompleto. Esses dados mostram que 24\% dos professores que estão atuando na educação básica brasileira ainda não têm formação em nível superior.

Outros dados do Anuário da Educação Básica (TODOS PELA EDUCAÇÃO, 2016) registram que, na Região Nordeste, dos 626.643 professores, $37 \%$ ainda não têm formação superior. Já no Maranhão, de um total de 98.892 professores da educação básica, 49,6\% encontram-se sem nível superior. Tanto a Região Nordeste quanto o Maranhão precisam avançar no quesito formação docente, o que só será possível com sólidas políticas públicas de formação de professores.

Ademais, o Relatório do $1^{\circ}$ Ciclo de Monitoramento das Metas do PNE: biênio 2014-2016 (BRASIL, 2016) aponta que dos professores da educação básica com formação superior, ou seja, 1.670 .823 docentes, somente 52,5\% possuem curso superior compatível com a disciplina lecionada; a Região Nordeste e o Maranhão possuem os índices mais baixos de compatibilidade, com $38,2 \%$ e $26,1 \%$, respectivamente.

Diante desse quadro sombrio que denuncia o descaso do poder público com a formação docente e com a qualidade da educação básica, faz-se necessário avançar tanto qualitativamente quanto quantitativamente nas políticas de formação docente, visando à profissionalização desses professores que já atuam na rede pública de ensino da educação básica. Mesmo que alguma política tenha sido instituída desde 2009, como por meio do Decreto $n^{\circ} 6.755 / 2009$, que se coloca enquanto mecanismo institucional para viabilizar a formação desses professores, a sua existência ainda não é suficiente.

Destaca-se ainda que, nesse mesmo decreto, está definida a atuação da CAPES quanto à oferta de programas de formação inicial e continuada para os professores da Revista Labor Edição Especial 
educação básica. Logo, interessa aqui registrar que, nesse decreto, já fica também instituída a atuação da CAPES que, dentre outras ações, prevê a "oferta emergencial de cursos de licenciaturas e de cursos ou programas especiais dirigidos aos docentes em exercício há pelo menos três anos na rede pública de educação básica que sejam graduados", mas que ainda não possuam licenciatura na área de atuação da educação básica e sim em área diversa da atuação docente (BRASIL, 2009, grifos nossos).

Posteriormente, foi criado o Plano Nacional de Formação dos Professores da Educação Básica - PARFOR que, na modalidade presencial, conforme o Manual Operativo, "é um Programa emergencial, criado para atender o disposto no artigo 11, inciso III do Decreto $n^{\circ} 6.755 / 2009$, tendo como objetivo induzir e fomentar a oferta de educação superior, gratuita e de qualidade, para professores em exercício na rede pública de educação básica”. Com essa ação, ampliam-se as possibilidades de atendimento desse público específico, de acordo com a determinação da LDB no 9.394/96, no que se refere à formação de professores da educação básica desde 2009 (BRASIL, 2013).

Ainda no mesmo Manual está estabelecido que o acesso dos docentes à formação requerida na $\mathrm{LDB} \mathrm{n}^{\circ}$ 9.394/96 é realizado por meio da oferta de turmas especiais em Instituições de Educação Superior (IES), nos seguintes cursos: Primeira Licenciatura, Segunda Licenciatura e Formação Pedagógica.

Este estudo tomou como eixo de análise os cursos de primeira licenciatura do PARFOR que se destinam aos docentes ou tradutores intérpretes de Libras em exercício na rede pública da educação básica. O propósito é apreender e analisar as necessidades formativas e a formação de competências para o desenvolvimento de práticas pedagógicas inovadoras nas escolas públicas do Maranhão.

A partir do exposto, entende-se que os cursos implantados por meio do PARFOR, denominados de Primeira Licenciatura, estão voltados para a aquisição de licenciatura plena, conforme exigências estabelecidas pela Resolução $n^{\circ} 2$, de $1^{\circ}$ de julho de 2015, do Ministério da Educação, via Conselho Nacional de Educação, que define as Diretrizes Curriculares Nacionais para a formação inicial em nível superior.

Esse processo formativo, desde sua implantação, tem gerado expectativas quanto à melhoria da educação básica no país. Porém, ao lado destas, vêm também as preocupações, tendo em vista que as novas exigências do mundo globalizado, ou seja, os sujeitos mais qualificados e competentes, determinam inúmeras reformas, como ressaltam Ramalho, Nuñez e Gauthier (2004): 
$\mathrm{Na}$ maior parte dos países, o novo século vem acompanhado por reformas educacionais orientadas para adequar a educação às exigências dos novos tempos e contextos, tais como a globalização das economias, as atuais políticas públicas e especialmente os impactos das novas tecnologias e formas de comunicação. Nessa situação, o conhecimento e a educação passam a ter um valor de grande importância, assim como a formação do professor torna-se um campo de sérios desafios (RAMALHO; NUÑEZ; GAUTHIER, 2004, p. 18).

De fato, a formação dos profissionais do magistério, neste século, tornou-se um desafio. Por isso, concorda-se com os autores citados quanto à preocupação em se discutir a profissionalização docente em todos os seus aspectos: históricos, sociológicos, filosóficos e práticos, dentre outros.

Discutir a profissionalização docente e sua identidade enquanto profissão constitui um desafio teórico e prático, já que a docência tem características e se desenvolve em situações específicas, o que lhe outorga uma dada singularidade em relação a outras atividades reconhecidas como profissões (RAMALHO; NUÑEZ; GAUTHIER, 2004, p. 18-19).

Nesse contexto, as pesquisas e dados sobre a educação no Brasil têm demonstrado que se precisa avançar na qualidade da educação básica e na formação e profissionalização docente. Os processos formativos criados nos últimos oito anos, sobretudo através das políticas educacionais instituídas pelo MEC e implantadas pela CAPES, como o PARFOR, especificamente os cursos de Primeira Licenciatura, retratam essa necessidade.

Entende-se que o processo de formação tem como um dos eixos a formação de competência. Nesse sentido, a formação e profissionalização docente, como bem explicitam Ramalho, Nuñez e Gauthier (2004), guardam suas especificidades, pois é o que irá orientar sua ação de forma responsável e comprometida a partir da unidade entre teoria e prática, ou seja, por meio de uma ação refletida que gera uma ação renovada, ou a práxis educativa. Igualmente, as competências "constituem qualidades do profissional que lhe permitem desenvolver determinadas atividades socialmente úteis, com sucesso e responsabilidade ao longo do seu desenvolvimento profissional" (RAMALHO; NUÑEZ; GAUTHIER, 2004, p. 72).

A necessidade de formação de novas competências profissionais é determinada pelo contexto social, político, econômico e cultural de um determinado tempo histórico e de um determinado espaço geográfico. Considerando o tempo histórico desta pesquisa, que tem como elemento central as profundas transformações decorrentes da segunda crise global do 
capital, com seus primeiros sinais no final da década de 1960 e início da década de 1970, deve-se atentar para as necessidades formativas determinadas por esse tempo histórico e pelo espaço em que atuam os sujeitos desta pesquisa, ou seja, os professores da educação básica das escolas públicas do estado do Maranhão. Esses professores são formados ou se encontram em processo de formação pelo modelo dos programas emergenciais, como o PARFOR/UFMA.

A partir desse fato, compreende-se que necessidades formativas são entendidas como produto das relações sociais mediadas pelas atividades humana, mas que, ao longo da história sofreram significativas mudanças como reflexo das transformações ocorridas no contexto em que estão inseridas. Por certo, entende-se que as necessidades formativas, por si sós, não se explicam. Nesse caso, compreendê-las significa, antes, buscar suas explicações em outros fatos sociais. Essa perspectiva de análise impõe a categoria da totalidade social como um dos aportes essenciais neste estudo. Sobre isso, de acordo com Kosik (2002 p. 41),

Totalidade não significa todos os fatos. Totalidade significa: realidade como um todo estruturado, dialético, no qual ou do qual um fato qualquer (classes de fatos, conjuntos de fatos) pode vir a ser racionalmente compreendido. Acumular todos os fatos (reunidos em seu conjunto) não constitui, ainda, a totalidade. Os fatos são conhecimentos da realidade se são compreendidos como fatos de um todo dialético [...] - se são entendidos como partes estruturais do todo.

Diante do exposto, tem-se a clareza de que o objeto de pesquisa que se quer conhecer encontra-se engendrado em um todo estruturado e em constante movimento: ao mesmo tempo em que determina é também determinado pelas complexas relações que se estabelecem no processo de sua materialização, o qual está inserido em uma totalidade. Então, por mais que se queira conhecer o objeto por completo, este será sempre um conhecimento inacabado por se encontrar em constante movimento.

Para dar sustentação a este estudo, optou-se inicialmente pelo conceito de necessidade, por se considerar uma palavra polissêmica, que se caracteriza de acordo com o contexto, espaço, tempo e por estarem ligados aos valores, desejos, aspirações, carência, falta, ao que é imprescindível, útil e necessário tanto aos sujeitos quanto ao meio social (LALANDE, 1993; HOUAISS, 2009 OUTHWAITE; BOTTOMORE, 1996).

A necessidade encontra-se intrinsecamente ligada à luta pela sobrevivência, pois as primeiras necessidades básicas do homem são alimentar-se, vestir-se, agasalhar-se, ou seja, o que move o homem é a necessidade. À medida que essas necessidades vão sendo satisfeitas 
pelas ações provenientes dos meios de produção e das relações sociais, novas necessidades vão emergindo, possibilitando ao homem criar e recriar sua história enquanto ser social, dotado de necessidades materiais e espirituais, e que age sobre elas por meio da atividade que desenvolve como mecanismo de realização.

Para tanto, os pressupostos epistemológicos da Teoria da Atividade, de Aléxie Nikoláevich Leontiev (1983), são alguns dos fundamentos para se investigar as necessidades formativas dos professores. De acordo com os estudos desse teórico, a atividade se materializa a partir de ações instigadas por necessidades e motivos. Dessa forma, Leontiev (1983, p. 147) denomina atividade como "al proceso que se es estimulado y orientado por un motivo enelcual esta objetivada una u outra necesidad”. Já para Núnez e Ramalho (2008 p. 28),

na Teoria da Atividade de A. N. Leontiev a atividade humana é considerada o processo que media a relação entre o ser humano (sujeito da atividade) e a realidade a ser transformada por ele (objeto da atividade). Nela podem ser evidenciados dois objetos: o conteúdo da cultura profissional, como objeto do conhecimento, e o professor, como sujeito do seu desenvolvimento profissional. Nesse caso o objeto coincide com sujeito. A formação como atividade relaciona o professor com o objeto da atividade profissional, como processo vital para a realidade profissional.

Nesse sentido, esta pesquisa teve como propósito detectar as necessidades formativas dos professores que estão em formação nos cursos de Primeira Licenciatura do PARFOR/MA, tendo como um dos fundamentos epistemológicos a Teoria da Atividade (LEONTIEV, 1983). O objetivo é analisar as relações existentes entre a emergência dessas necessidades e a formação inicial, considerando o modo como essa atividade de formação pode contribuir para a superação das necessidades no âmbito da prática pedagógica dos professores. Vale ressaltar que esses professores já se encontram no processo de desenvolvimento da profissão docente.

Estabelece-se, portanto, uma correlação entre necessidades, motivos e atividades, pois de acordo com Leontiev (1983), a atividade precisa coincidir com um motivo ou motivos e necessidades. Assim, ao se considerar que a atividade do professor é uma atividade tanto laboral quanto didática, e, acima de tudo, sensitiva, a qual tem como meta central a aprendizagem de outros sujeitos, pode-se afirmar que as necessidades, nesse caso as formativas, emergem das relações sociais do sujeito em um dado contexto histórico, político, social e cultural. 
Com essa visão ampla de necessidades formativas, as quais podem ser trabalhadas pela formação inicial como atividade principal nesse processo, aponta-se que o sujeito adquire conhecimentos profissionais não só dentro da escola, mas também fora dela, isto é, no ambiente de trabalho. Não se pode compreender as necessidades formativas de professores aprisionando-as na escola, até porque os fatos que ocorrem dentro dela só se explicam pelas inter-relações com os fatos que ocorrem fora dela.

\section{CONSIDERAÇÕES FINAIS}

A formação inicial de professores em serviço, nesse contexto, é entendida como uma atividade que possibilita a superação de necessidades a partir da apropriação dos conhecimentos necessários e adequados, visando ao desenvolvimento profissional docente e à melhoria da prática pedagógica. Ao mesmo tempo, tal formação possibilita a própria reconstrução da identidade docente, pois esta é construída e reconstruída no movimento das relações sociais, as quais são determinadas no contexto histórico social que o sujeito - neste estudo o professor, encontra-se inserido.

Compreende-se ainda que as políticas educacionais elaboradas e implantadas atualmente para a formação docente colocam-se como mais uma categoria de análise para a compreensão deste objeto de estudo, pois são as políticas educacionais que legitimam, no campo da legalidade, os formatos ou os tipos de formação docente destinados aos professores da educação básica pública. Tais políticas vêm se materializando por meio de programas e projetos, os quais são institucionalizados pelos decretos e resoluções.

Conclui-se, neste estudo, que o esforço de apreender as necessidades formativas para formar as competências necessárias na prática pedagógica é um desafio no âmbito da profissionalização docente, e imprescindível para a melhoria da educação básica das escolas públicas do Maranhão.

\section{REFERÊNCIAS}

BRASIL. Censo Escolar da Educação Básica 2015: resumo técnico. Brasília, DF, 2016.

Relatório do primeiro ciclo de monitoramento das metas do PNE: biênio 20142016: resumo técnico. Brasília, DF, 2016.

Coordenação de Aperfeiçoamento de Pessoal de Nível Superior. Manual operativo do plano nacional de formação de professores da educação básica. Brasília, DF, 2013. 
Ministério da Educação e Cultura. Resolução n ${ }^{\circ}$ 2, de $1^{\circ}$ de julho de 2015. Define as diretrizes curriculares nacionais para a formação inicial em nível superior (cursos de licenciatura, cursos de formação pedagógica para graduados e cursos de segunda licenciatura) e para a formação continuada. Ministério da Educação. Brasília, DF, 2015a. Disponível em: <http://pronacampo.mec.gov.br/images/pdf/res_cne_cp_02_03072015.pdf>. Acesso em: 23 jan. 2016.

Lei $\mathrm{n}^{\circ}$ 9.394, de 20 de dezembro de 1996. Estabelece as diretrizes e bases da educação nacional. Presidência da República Casa Civil. Brasília, DF, 1996. Disponível em: <http://www.planalto.gov.br/ccivil_03/leis/L9394.htm>. Acesso em: 13 jun. 2015.

Decreto $n^{\circ} 6.755$, de 29 de janeiro de 2009. Institui a Política Nacional de Formação de Profissionais do Magistério da Educação Básica, disciplina a atuação da Coordenação de Aperfeiçoamento de Pessoal de Nível Superior - CAPES no fomento a programas de formação inicial e continuada, e dá outras providências. Presidência da República Casa Civil. Brasília, DF, 2009d. Disponível em: <http://www.planalto.gov.br/ccivil_03/_ato20072010/2009/decreto/d6755.htm>. Acesso em: 10 jun. 2016.

HOUAISS, Antonio; VILLAR, Mauro de Salles; FRANCO, Francisco Manuel de Mello. Dicionário Houaiss de Língua Portuguesa. Rio de Janeiro: Objetiva, 2009.

KOSIK, Karel. Dialética do concreto. Rio de Janeiro: Paz e Terra, 2002.

LALANDE, André. Vocabulário técnico e crítico da filosofia. São Paulo: Martins Fontes, 1993.

LEONTIEV, Aléxei. Actividad, conciencia e personalidad. La Habana: Editorial Pueblo y Educación, 1983.

NÚÑEZ, IsauroBeltrán; RAMALHO, Betânia L. A profissionalização da docência: um olhar a partir da representação de professoras do ensino fundamental. Revista Iberoamericana de Educación, n. 46/9, p. 1-13, set. 2008. Disponível em:

$<$ http://www.comperve.ufrn.br/conteudo/observatorio/arquivos/artigos/profissionalizacaodocencia.pdf>. Acesso em: 26 abr. 2014.

. Os professores no ensino médio inovador no $\mathbf{R N}$ : crenças, necessidades formativas e inovação pedagógica. 2013. Projeto de Pesquisa (Pós-Graduação em Educação) - CNPq, Programa de Pós-Graduação em Educação, Natal, 2013. Mimeografado.

OUTHWAITE, Willian; BOTTOMORE, Tom. Dicionário do pensamento social do século XX. Rio de Janeiro: Jorge Zahar Editor, 1996.

RAMALHO, Betania L.; NÚÑEZ, Isauro B.; GAUTHIER, Clermont. Formar o professor, profissionalizar o ensino: perspectivas e desafios. 2. ed. Porto Alegre: Sulina, 2004.

TODOS PELA EDUCAÇÃO. Anuário da educação básica. 2016. Disponível em: <http://www.todospelaeducacao.org.br/educacao-na midia/indice/30928/documento-ajudaescolas-a-implementar-inovacoes/>. Acesso em: 10 set. 2016. 